\title{
A PSYCHOANALYSE DOS SONHOS
}

A doutrina de Freud, hoje universalmente conhecida pelo nome de psychoanalyse, nome dado pelo seu autor, é, ao mesmo tempo, uma psychologia e um methodo de investigação e therapeutica mentaes.

Esta doutrina é celebre sobretudo pela importancia que attribue aos phenomenos da sexualidade no desenvolvimento das nevroses e psychoses.

As pesquizas iniciaes de Freud versavam sobre a pathogenia da hysteria e foram executadas com um fim puramente therapeutico.

Os seus estudos, entretanto, á proporção que iam procurando analysar as causas dos smptomas da nevrose, e o mecanismo a sua determinação, levaram-no, pouco a pouco, a construir todo um systema psychologico, que se baseia na concepção da vida mental como um conjuncto em perpetuo movimento e em continua evolução, cuja dynamica repouøa sobre o inconsciente, conceito já antigo e empirico, mas que elle alargou e transformou de um modo singular e suggestivo.

As suas conclusces tirou-as Freud de seu methodo de analyse, que se aproveita de todas as manifestações inconscientes ou involuntarias, come as attitudes, os lapsos, os esquecimentos, a inspiração artistica, e dos symptomas das nevroses e psychoses para chegar até ao inconsciente do individuo e determinar-lhe as tendencias e sentimentos mais profundos, os pensamentos reprimidos ou a idéa pathogenica. Porque para Freud, toda a nevrose, psy-

:e ou psychonevrose é determinada por um complexo affectivo (como elle chama a um conjuncto de tendencias e sentimentos em volta de um motivo central) que traumatisa o inconsciente, desharmonisando o concerto psyrhico, com um mecanismo de que mais adiante tratarei.

Muitos dos pontos basicos da psychoanalyse já tinham sido estabelecidos anteriormente e mesmo já faziam parte da psychologia admittida quando Freud iniciou as suas pesquizas.

Mas a vantagem do professor de Vienna foi justamente ter retomado certás idéas já estabelecidas, insistindo sobre ellas, alarsando-as 3 integrando-as numa synthese que abrange toda a psychologia normal e pathologica.

o objectiro deste artigo é apenas expor uma psychoanalyse dum sonho, mas vão antes umas linhas sobre o conceito da vida 
mental, admittido por Freud, e sobre o valor e interesse que apresenta a analyse dos sonhos.

O individuo póde ser considerado sob dois pontos de vista: como ser isolado e como ser pertencente a uma série de seus semelhantes, tendendo toda a sua actividade para dois fins: conserval-o e perpetuar a especie.

Essa actividade tem como elementos essenciaes, o instincto de conservação e o instincto sexual.

Freud chama ao complexo das tendencias sexuaes de libido.

Reduzem-se, assim, na essencia, os impulsos vitaes e, portanto, os psychicos, em egoismo e libido.

O fim ultimo do instincto sexual é a posse do ser do sexo opposto. Mas como esse fim, instinctivo e ancestral, tem um caracter absorvente e avassalador, e como a sua realização se faz debaixo de todas as complicações da vida em sociedade, as tendencias sexuaes se complicaram de tal fórma, se mascararam com taes artes, deslocando-se, até, da finalidade primitiva, que a libido, para a sıa expansão, tornou-se polymorpha e quasi ubiqua $\left(^{\star}\right)$ expandindo-se num incommensuravel numero de manifestações da actividade humana, sem se limitar apenas, aos actos visivel e grosseiramente sexuaes, como á primeira vista podia parecer

Um dos pontos essenciaes nesta theoria é a evolução do instincto sexual na infancia, a que Freud attribue uma importancia capital, considerando as suas perturbações e as recordações eroticas da criança como a base das manifestações morbidas que o adulto possa apresentar

Além disso, as funcções psychicas têm dois dominios: o consciente e o inconsciente.

Os phenomenos psychicos que se passam fóra do campo da consciencia são muito mais numerosos, mais complexos e mais profundos que os que se passam sob o nosso conhecimento.

Os processos conscientes não representam senão fracções da vida psychica total o processo psychico não é necessariamente consciente e o eu está reduzido a se contentar com dados raros e fragmentarios sohre o que se passa fóra do alcance da introspeç̧ão .

(*) Freud procurá, mesmo, identificar o egoismo e a libido num só inıpulso sexual, fundamental e unico, o que faz que a sua deutrina mereça o sentido de pansexualiømo, que lhe foi dado ha muito tempo. 
O termo inconsciente foi tomado acima num sentido muito geral Podemos subdividil-o em dois campos: o preconsciente (ou sub-consciente) e o inconsciente, propriamente dito.

E' de facil veríficação o facto de não se poder pensar simultaneamentc em varias coisas. Ellas têm de se succeder numa corrente continua, occupando a consciencia apenas uma ou algumas de cada vez

Ora, os elementos que nós vamos armazenando durante o correr da vida e que podem assim, ser transportados para o campo da consciencia por um esforço de memoria, ou que se transportam expontaneamente, esses elementos que são os conhecimentos adquiridos e concorrem para formar a experiencia individual, ficam latentes no preconsciente.

$O$ inconsciente propriamente dito encerra as tendencias mais profundas e todo o lastro hereditario e phylogenetico, donde par. tem as forças orientadoras da actividade psychica.

O inconsciente corresponde á actividaed psychica primaria e é incapaz de accesso na consciencia.

o preconsciente: actividade psychica secundaria, está collocado entre o inconsciente e o consciente e havendo uma penetração mutua desses tres dominios, não se póde precisar onde começa um e o outro acaba

O preconsciente é ao contrario, directa e immediatamente capaz de consciencia. Os seus elementos a alcançam apenas tenham satisfeit, a algumas condições, como, por exemplo, attingirem uma certa intensidade e terem voltada sobre si uma parte de attenção.

Além da nossibilidade de consciencia, os elementos do preconsciente ainda tendem para ella, podendo-se comparar esta tendencia á que um corpo mais leve que a agua, e nella mergulhado, tem de se projectar á tona. Estas mudanças de estado (do preconsciente ao consciente) dos elementos psychologicos, ora com apparencias de expontaneidade, ora suggeridos por impressões da occasião, são continuas e em perpetua evolução, e assim a consciencia nunca está livre e sempre se pensa em alguma coisa. Mas não pensamos no que queremos: mas no que se impõe ao pensamento; todo estado de consciencia é determinado e toda a idéa é o extremo de uma série de elementos presos uns aos outros e mergulhados, na quasi totalidade, profundamente no inconsciente.

Todo elemento psychologico consciente, subentende, pois, necessariamente, ur processo previamente realizado e continuo e de que elle é um fragmento transitoriamente isolado na conseiencia .

Pois bem, Freud pretende pelo processo da psychoanalyse chegar, partindo duma determinada idéa, ao conhceimento retrospe- 
ctivo do processo inconsciente que a gerou e descobrir os elementos da cadeia, procurando, assim, dar á idéa o seu determinismo e significação

Todas as impressões trazem comsigo uma certa energia que uma vez no preconsiente, permanecem latentes, com tendencia a se actualizar Nem todos os elementos porém, se objectivam no campo da consciencia, da mesma fórma que nem todos os nossos pensamentos se transformam em actos. Mas a tendencia fica, aguardando uma opportunidade de objectivaçāo.

A vida em sociedade $\boldsymbol{e}$ o contacto com a realidade obrigam 0 individuo a se adaptar e a adaptação se faz a custa de forças coercitivas: a educação, a ethica, o sentimento moral, religioso, etc., que se resumem, todas, na consciencia moral.

Quando uma tendencia vai de encontro ás conveniencias, quando repugna ou é prejudicial ao individuo, este a recalca, isto é, afasta-a da consciencia, procurando tirar-lhe qualquer possibilidade de realização.

Assim, quando uma circumstancia q iquer lembra a um viduo nornal a possibilidade de um acto profundamente immoral, como um incesto, por exemplo, sabemos com que força intervem o recalcamento para repellir o desejo repugnante.

Pois bem, a esta força que existe no limiar da consciancia e que é como um fiscal que escolhe as tendencias candidatas a surgirem no nosso scenario consciente, Freud chama censura.

A ação da censuva, retendo no preconsciente certos complexos affectivos e não lhes tirando, entretanto, a energia e a interferencia no concerto psychico, cria a possibilidade de uma eclosão intempestiva e anarchica, que vai constituir o que Freud chamou os traumatismos psychicos.

Podem-se comparar estes factos ao que se observa com as infecções banaes, anonymas e transitorias, adquiridas durante 0 correr da vida e que mais tarde, quando uma opportunidade qualquer se apresentar, vão ser as causas, até então latentes de symptomas e molestias, apparentemente isolados desses antecedentes banaes e fugazes, de que nem mesmo o paciente se recorda. Os symptomas e molestias seriam os traumatismos de Freud, e consequente symptomatologia morbida e as infecções, os elementos latentes do preconsciente, que se manifestam assim que se offereça a occasião.

E os sonhos? Estes são as manifestações, com maior ou menor intensidade de consciencia, da actividade psychica que acompanho somno. 
Resuitam de um tecido vario de imagens e idéas fugazes, d trama debil e irregular A ordem logica.geralmente falta, o que lhe dá a sua inçherencia notavel (Luciani).

Mas, "para a psychoanalyse o sonho absolutamente não é um acaso, uma desordem psychica; $\dot{\theta}$ um acto psychico essencial, determinado, nos seus menores detalhes, por leis psychologicas precisas" (Regis et Hesnard)

E essas leis confirmam a hypothese da existencia latente dos complexos affectivos, a que nos referimos atrás.

Durante o somno (pelo menos nas phases em que é acompa. nhado de sonhos) a consciencia não desapparece de todo e o individuo mantém a sua personalidade, que póde conservar ou modificar a sua orientação.

Os sonhos são, portanto, as projecções conscientes, durante o somno, de um certo numero de elementos representativos. Ora, esses elementos surgen. do preconsciente, onde aguardavam uma op portunidade de libertação.

Mas, sonha-se com todos os elementos do preconsciente ao mesmo tempo?

Não, só com alguns: aquelles que estão associados a uma im. pressão que tenha attingido o individuo na vigilia, ou mesmo durante o somno, impressão essa que vai ser a causa, não efficiente mas accidental do sonho e que Freud compara a um empreiteiro que reune os operarios para realizar uma obra.

O sonho é, pois, uma descarga de elementos que estavam presos no preconsciente.

Das impressões da vigilia, nem todas, porém, vão figurar no sonho: só figuram as que não tiveram tempo ou occasião de umi elaburacão consciente; as que, apenas penetraram do mundo exterior ao interior, pelos orgãos dos sentidos, foram logo varridas da consciencia for obra da censura (censura na sua significação mais geral. isto é, actividade seleccionadora por um processo de inhibição, sempre orientada pelo criterio individual)

As manifestacões objectivas dos sonhos, são, para os effeitos le uma analyse, insignificantes, pois que se reduzem a movimentos modificações mimicas da face, a uma ou outra phrase articulada, , pouco mais, excepto, naturalmente, $o_{\mathrm{S}}$ casos pathologicos.

o methodo a que se tem de recorrer será, pois, a introspecção isto é, o exame subjectivo feito pelo sonhador, depois de despertar. sendo, por isso, os proprios sonhos os que melhor se analyzam.

O sonho destinado á psychoanalyse deve ser escripto immediatamente após o despertar, quando estão ainda mais ou menos vivas as suas imagens na memoria. 
Para a analyse dos sonhos alheios tem-se que exigir absoluti isenção $\theta$ sinceridade de sonhador, não se admittindo nenhum. critica ou recusa por parte deste, sob pena de não sahir coisa dign: de se tomar a

o methodo analytico será, neste caso, subjectivo e objectiv a um tempo: objectivo para quem analysa e subjectivo para o paciente, que se sujeita a uma verdadeira anamnése que tem por fim revelar todas as associações de idéas suggerida ${ }_{S}$ pelo sonho.

O sonho que vai abaixo não é meu, mas de um paciente que não tendo commigo nenhum motivo de constrangimento, sujeitouse com muita docilidade e franqueza ao interrogatorio.

Por ser este longo e minucioso, só figurarão aqui algumas informações uteis obtidas, e, para resumir, o paciente será chamado A

$\mathrm{Na}$ analyse que se segue procurarei mostrar apenas: o mo tivo immediato do sonho, a identidade affectiva dos seus elementos e a sua finalidade, aliás commum a todos os sonhos - a satisfacção de um desejo, conforme estabeleceu Freud como lei geral.

O sonho escripto por $\mathbf{A}$ immediatamente após o despertar, é o seguinte.

"Sonhei aue estava sentado num sofá, collocado a um canto duma pequena sala, separada de outra, maior, por um biombo de madeira. Ao lado achava-se uma mulher (a que eu chamarei sra. $\mathrm{X}$ ), bonita e bem vestida, cercada de $\operatorname{algun}_{\mathrm{S}}$ homen $_{\mathrm{S}}$ que a assediavam com propostas e insinuações a que ella resistia, mostrandose visivelmente contrariada.

$\mathrm{Eu}$, que a conhecia, sentia impetos de soccorrel-a, mas não me levantava, acovardado.

A mulher e o grupo de homens que a cercava, dirigiram-se. pela porta do biombo que fazia communicar as duas salas, á sala maior, continuando o mesmo assedio e resistencia.

$\mathrm{Eu}$, que me inha levantado, via, através da porta, a mulher voltando depois de se ter livrado dos homens, os quaes eu via pelas costas, mal os distirguindo num fundo escuro para onde se dirigiam.

Como nos conhecessemos, ella se dirigiu a mim, como a al guem que the pudesse valer.

Recebi-a nos braços, disse-lhe algumas palavras amigas, expro bei os homens, $\boldsymbol{\theta}$, sbraçando-a com todas as apparencias de res peito, beijel-a na teota.

Este beljo, sentia-o no sonho, velava uma segunda intençãc inconfessavel a respeito da mulher" 


\section{PGYChoanalys:}

Comocei perguntando ao individuo se havia alguma impressão de vigille (do mesmo dia ou de dias anteriores) que se pudesse relsolonar com o sonho e pedi-lhe tambem todas as associaᄃões immudiatas que o sonho suggerisee.

Resumo anul as informagres: na mesma noite do sonho, A ti. nica jdo, em companhis de um amigo, a uma pension qualquer. Por varios motívos, não conseguiu dar satisfacção á pensionista, de1xando-a sem the ter dato ao que ta.tors

Conton o aco ac amigo, riram, mudaram de assumpto, desvanecendo-se completamente a lembrança do facto, do qual não se lembrou mals so reato da notte.

A sra. X uma pessoa das relações de $A$, a quem este tem em muita consideração.

- $\mathrm{O}_{\mathrm{S}}$ homens n⿳̆ apparecem muito nitidos e A não denuncia nelles nenhum conhecido ou pessoa de que se possa recordar.

A sala em que ge passa a scena, o sofá, em que apparece sen. tado, e o biombo de madeira, são de uma pensão onde A. morou por rouco tempo.,

Note-se, em primeiro logar, que este sonho é muito simples e muito nitido, desenrolando-se as scenas com muita clareza e or dem, sendo tambem muito nitido o sentimento que $\mathbf{A}$ experimentavi -m sonho, no qual, como elle mesmo diz na descripção, se sentia acovardado, não escondendo uma intenção inconfessavel.

Ora, este sentimento não se póde relacionar legitimamente com $\checkmark$ facto da vigllia - a frustação de uma. tentativa ?

E' o que parece. Com effeito, o deixar-se um couple sem se ter mostrajo uma certa viacidade, não é dos factos que mais nos oxaltem...x.1

Ora, antes do sonho, $\mathbf{A}$ afastou da sua consciencia esse facto desagradavel, pols que delle năo se recordou mais no resto da noite.

Portanto, o Individuo em questãa recalcou, antes do sonho ama idéa humilhante.

Ora, esse sentimento de impotencia que, nem bem surgiu, fo; varrido do campo da consciencia, recalcando-se no subconsciente, apparece nitidamente no sonho que serviu, assim, de valvula de escoamento de sua energla latente.

Parece que isto, por emquanto, não é forçar as analogias.

Toda 1dea desperta um estado d'alma que o Individuo procur: conservar on repellit conforme a sua tonalidade affectiva, isto é, conforme aja agradavel on desagradavel. A lembrança de um t:iumpho, por exenplo, enbela-nos por multo tempo, ao passo que 
todos nós procuramos afastar da memoria um feio acto que te nhamos commettido, não admittindo que outros nos venham recor dalto.

Os estados d'alma ou tendencias, que, na vigula sao constran. gidos ou revellidos por serem chocantes ao caracter ou por serem desagradaveig e inopportunos, no sonho se expandem com mais liberdade, pelo afrouramento do rigor da censura durante o somno $\therefore$ qual todavia năo co dervanece de todo.

E' o que se verifica neste sonho, no qual o paciente assume uma attitude simplesmente inferior: observa uma senhora cercada cle homens que lhe disem coisas sordidas, quer intervir e se aco. varda; depois recebe-a como amigo e dá-lhe um beijo que masca rava uma segunda intenção.

Note-se este pormenor - que o beijo foi dado na testa - si ti. destinadóas beljos paternaes, o que mostra o interesse que tinha A em dar uma fórma respeitosa á sua intenção. pelo prestigio que, mesmo no sonho, continuava a exercer a sra. $X$; note-se tamben a baixa consideravel que soffreu a sua mentalidade, sob o ponto de vista moral. E' como se vê, um borbulhar muito pouco edificante.

Vejamos, agora. a significação dos outros elementos.

$A$ sra. $\mathbf{X} 6$ conhocida $\theta$ respeitada por A. Ello tem, entretanto motivos para figurar o sonho: é que, mezes antes, $A$ teve que lhi pedir desculpas por não a ter cumprimentado em certa occasião: a lembrança deste facto faz que este elemento - sra. $X$ ligue directamente ao sentimento geral de constrangimento, que domina o sonho.

A, boijando-a, parece que quer realizar uma vingança do que o obrigon o prestiglo da dama em questão. Além disso, sendo $X$ uma mulher, nada mais razoavel que figure em tal sonho, apesar dc nunca ter despertado desejo sexual consciente em $\mathbf{A}$.

Mas porque foi ella e não outra qualquer?

Pela idontidade affectiva que a ligava ao resto do conteudo do sonho, como mostrei acima.

Os personagens masculinos são todos anonymos e talvez não sejam mais que o symbolo da concorrencia.

A elles nada o paciente associa de positivo.

o scenario 6 muito simples. A reconhece como pertencente a uma pensão onde morou por muito curto prazo, justamente por nella se sentir em desconforto. O scenario lembra, portanto, o mesmo sentimento geral predominante no sonho, o que se dá com todos os outros elementos, que se associaram expontaneamente po: provocarem, uns com maior, outros com menor intensidade, a mes ma tonalidade affectiva. 
Este sonho tem um fundo nitidamente sexual, o que é muit trequente, e mesmo predominante na genealogia dos sonhos, sem ser. todavia, regra absoluta, pois não ha, para Freud, pansexualismo nessa determinação.

Segundo Freud, todo o sonho tem por fim a satisfacção de um desejo. Neste, o facto é typico: A satisfaz o seu desejo sexual, frustado na vespera, beijando $X$ em sonho, tendo se dado, neste exemplo, a transferencia do rlesejo de um objecto para outro.

Freud distingue nos sonhos duas ordens de elementos: as idéas latentes e o conteu'do figurado.

Este é o proprio conteu'do dos sonhos e representa as primeiras, isto é, os complexos affectivos recalcados que determinaram o sonho mas que, em vez de nelle surgirem taes quaes, se apresentam travestis, depois de terem soffrido um previo processo de deformação e disfarce, que os faz apparecer symbolisado $\$$ tos do conteu'do figurado.

Este processo de camouflage é realizado pela censura e, consistindo o sonho neste conteu'do, unico capaz de ser lembrado, vêse como $_{0}$ proprio individuo ignora as causas que the geram os sonhos.

Só se póde attingir essas causas pelo processo interpretativo da psychoanalyse

Qual é o mecanismo que regula a transformação das idéas latentes nas imagens do conteu'do figurado para a elaboração dos sonhos? Ou, qual é o mecanismo psychologico que regula a armação hos sonhos?

Freud estabelecen tres processos, como os mais geraes para essa elaboração, além de dar aos sonhos, como já vimos, a finalidade commum da satisfacção de um desejo.

Esse $_{S}$ processos, que são a dramatização, a transferencia e a condensação, nem semıore se verificam todos ao mesmo tempo, podendo se observar, ora juntos, ora isolados.

Neste exemplo verificam-se os tres, o que, aliás, é o caso mais geral.

A dramatizacão consiste na transformação dos elementos latentes do sub-conscierte em imagens e na sua enscenação verdadeiramente ailucinatoria. E' o processo essencial.

A condensação é um processo symbolico dos mais importantes e corsiste na representação de varias idéas anălogas num mesmo symbolo, syntheticamente. Este é o processo mais intellectual da 
elaboração, cuja complexidade corresponde ao desenvolvimento mental do indiviauo. Por isso, os sonhos das crianças são relativamente muito simples.

O terceiro processo consiste pa transferencia de um desejo de um objecto real a outro symbolizado em sonho.

Como se viu neste exemplo, A deslocon o objecto do seu desejo sexual da pensionista da vespera para a sra. $X$, que figura como svmbolo condensado de mais de uma mulher

\section{CONCLUSÃo}

A psychoanalyse dos sonhos é legitima, isto é, póde ser feita de accordo com regras estabelecidas pela observação dos factos. A sua legitimidare se mantém dentro de limites que possam permittir um controle acceitavel e sério que garanta o analysta da má fé das associações imaginosas, nas quaes fatalmente cahirá si quizer levar a analyse até onde estas o insinuarem.

Não ha duvida que o cunho pessoal, por emquanto irremovivel de certos methodos da psychologia, na analyse dos sonhos mais se accentu'a, o que não impede, entretanto, que, com uma noção exacta das medidas, se chegue á realidade effectiva, de um criterio psychoanalytico, aproveitando-se, segundo leis rigorosamente estahelecidas, essa importante manifestação objectiva que encontrou em Freud quem lhe desse a technica de analyse e talvez a verdadeira significação

A. ARRUdA SAMPaio
S. Paulo, outubro de, 1924

\section{BIBLIOGRAPHIA}

A bibliographia sobre a psychoanalyse é enorme. Além de bibliothecas e de livros em continua publicação, ha até revistas especializadas, destinadas a contribuições e propaganda. Disto póde dar uma idéa o catalogo bibliographico que acompanha a obra de Regis e Hesnard, abaixo citada.

AS obras de Freud, além de artigos esparsos, já formam uma collecção de varios volumes, que estão sendo traduzidos em todas as linguas, mas as duas que vão abaixo são as capitaes para o conhecimento da sua doutrina.

FREUD - Introdução á psychoanalyse (trad. franceza e hespanhola) E' um resumo completo de todas as theorias. 
FREUD - A interpretação dos sonhos (trad. hespanhola)

Obras de vulgarização e critica:

CHARLeS BLONDEL: La psychoanalyse (1924). Resumo da doutrina de Freud, cujas idéas, expostas com toda a clareza, são cerradamente criticadas.

REGIS et HESNARD - La psycho-analyse dan S $_{\mathrm{S}}$ les nevroses et psychoses (1914) Além da exposição clarissima, trata das applicações medicas e extra-medicas da psychoanalyse, terminando por uma critica das idéas de Freud sob os pontos de vista psychologico, medico e therapeutico. E' a melhor exposição franceza da doutrina.

1)R. FRANCO DA ROCHA - O pansexualismo na doutrina de Freud (1920). Talvez a unica publicação brasileira sobre o assumpto.

LUCIANI - Fisiologia dell'Uomo - V capitulo referente aos phenomenos psycho-physicos do somno e da vigilia.

MEDEIRos E ALBUQUERQUE - Este autor, admiravel vulgarizador, tem um volume muito conhecido, e, que, apezar de resumido, trata destes assumptos de uma maneira clara e accessivel - O Hypnotismo (2.a edição, 1923). Tem um capitulo sobre a doutrina de Freud.

Nestas indicações se encontrarão płeciosas informações bibliographicas.

\section{ASSIGNEM A "REVISTA DE MEDICINA"}

ESTRANGEIRO.

$10 \$ 000$

BRASIL ( 6 numeros)

$18 \$ 000$

NUMERO AVULSO 